\title{
Document-Engineering Methodology in Health Care: An Innovative Behavioral Science-Based Approach to Improve Patient Empowerment
}

\author{
Bernd Pohlmann-Eden ${ }^{1 *}, \mathrm{MD}, \mathrm{PhD}$; Silke C Eden ${ }^{2 *}$, MD \\ ${ }^{1}$ Department of Pharmacology \& Toxicology, University of Toronto, Toronto, ON, Canada \\ ${ }^{2}$ Problem-Based Online Health Consultancy, Toronto, ON, Canada \\ *all authors contributed equally
}

Corresponding Author:

Bernd Pohlmann-Eden, MD, PhD

Department of Pharmacology \& Toxicology

University of Toronto

Medical Sciences Building, 1 King's College Circuit

Toronto, ON, M5S 1A8

Canada

Phone: 16478061486

Email: bpohlmanneden@me.com

\section{Abstract}

Engaging patients in their treatment and making them experts of their condition has been identified as a high priority across many medical disciplines. Patient empowerment claims to improve compliance, patient safety, and disease outcome. Patient empowerment may help the patient in shared decision making and in becoming an informed partner of the health care professional. We consider patient empowerment to be in jeopardy if written medical information for patients is too complex and confusing. We introduce document-engineering methodology (DEM) as a new tool for the health care industry. DEM tries to implement principles of cognitive science and neuroscience-based concepts of reading and comprehension. It follows the most recent document design techniques. DEM has been used in the aviation, mining, and oil industries. In these very industries, DEM was integrated to improve user performance, prevent harm, and increase safety. We postulate that DEM, applied to written documents in health care, will help patients to quickly navigate through complex written information and thereby enable them to better comprehend the essence of the medical information. DEM aims to empower the patient and help start an informed conversation with their health care professional. The ultimate goals of DEM are to increase adherence and compliance, leading to improved outcomes. Our approach is innovative, as we apply our learning from other industries to health care; we call this cross-industry innovation. In this manuscript, we provide illustrative examples of DEM in three frequent clinical scenarios: (1) explaining a complex diagnosis for the first time, (2) understanding medical leaflet information, and (3) exploring cannabis-based medicine. There is an urgent need to test DEM in larger clinical cohorts and for careful proof-of-concept studies, regarding patient and stakeholder engagement, to be conducted.

(JMIR Hum Factors 2020;7(3):e19196) doi: 10.2196/19196

\section{KEYWORDS}

document design; 1-pager; empowerment; patient engagement; cognitive science; health care; cross-industry thinking; malpractice in health care; written information

\section{Setting the Scene}

The only thing more expensive than education is ignorance. [Benjamin Franklin]

Fortunately, modern medicine in the second millennium provides people in need of health care a constantly growing range of options, both in the diagnostic field and in the treatment field. Leading the way are the vast resources of medical information available on the web. Paradoxically, the described scenario can be overwhelming for the individual patient who finds it hard to navigate an increasingly complex health care system and make the right choices. In this manuscript, we postulate that there is a real need for well-designed and easy-to-understand written medical information to get patients 
engaged, informed, and ultimately empowered to positively impact their own disease outcomes.

Active engagement of patients and patient-centered care have been recognized for decades as priorities [1,2]; it has been suggested more specifically to enlist patients and families as allies in designing, implementing, and evaluating health care systems [1]. These concepts, driven by the vision to make the patient the expert, resulted in shared decision making, improved compliance, and improved adherence to medication [3]. Encouraging patient participation and self-management helped patients to gain control over their medical conditions and ultimately feel empowered [4,5]. How best to engage patients, doctors, and other stakeholders in designing comparative effectiveness studies has become an extensive field of research [6-8]. There is an ongoing need to investigate the dividends of engaged research and how to evaluate these effects [9].

Despite all these efforts, medical mistakes and malpractice still occur on a large scale. In North America, the number of people dying in hospitals as a result of malpractice and adverse drug events exceeds the number of deaths as a result of car accidents [10]. In a seminal paper almost 20 years ago-No Toyotas in health care: Why medical care has not evolved to meet patients' needs - the missing "business case of quality" in health care was criticized [11]. Meanwhile, many health care organizations adopted the Toyota Production System as the performance improvement approach, often called the LEAN health care management system [12]. The LEAN improvement process focuses on defining value from the patient point of view, mapping value streams, and eliminating waste in an attempt to create continuous flow [12]. These attempts are in line with the extensive quality improvement movement, which aims for better patient and population outcomes, better professional development, and better system performance [13]. Surprisingly, the scope of insufficiently written documents for malpractice in health care has never been systematically assessed in an epidemiological study. This finding is an interim result of an ongoing, not-yet-published, $\mathrm{PhD}$ research project at the University of Heidelberg, Germany, under supervision of the main author (BP). This is surprising, as written documents are used routinely at multiple intersections of an individually complex health care delivery process. These intersections include referral letters, information brochures about diseases, product information, consent forms, procedure guidelines, and treatment protocols (see Figure 1).

Figure 1. There are multiple steps in the successful delivery of health care with critical phases, where clearly written and easy-to-understand communication documents are key.

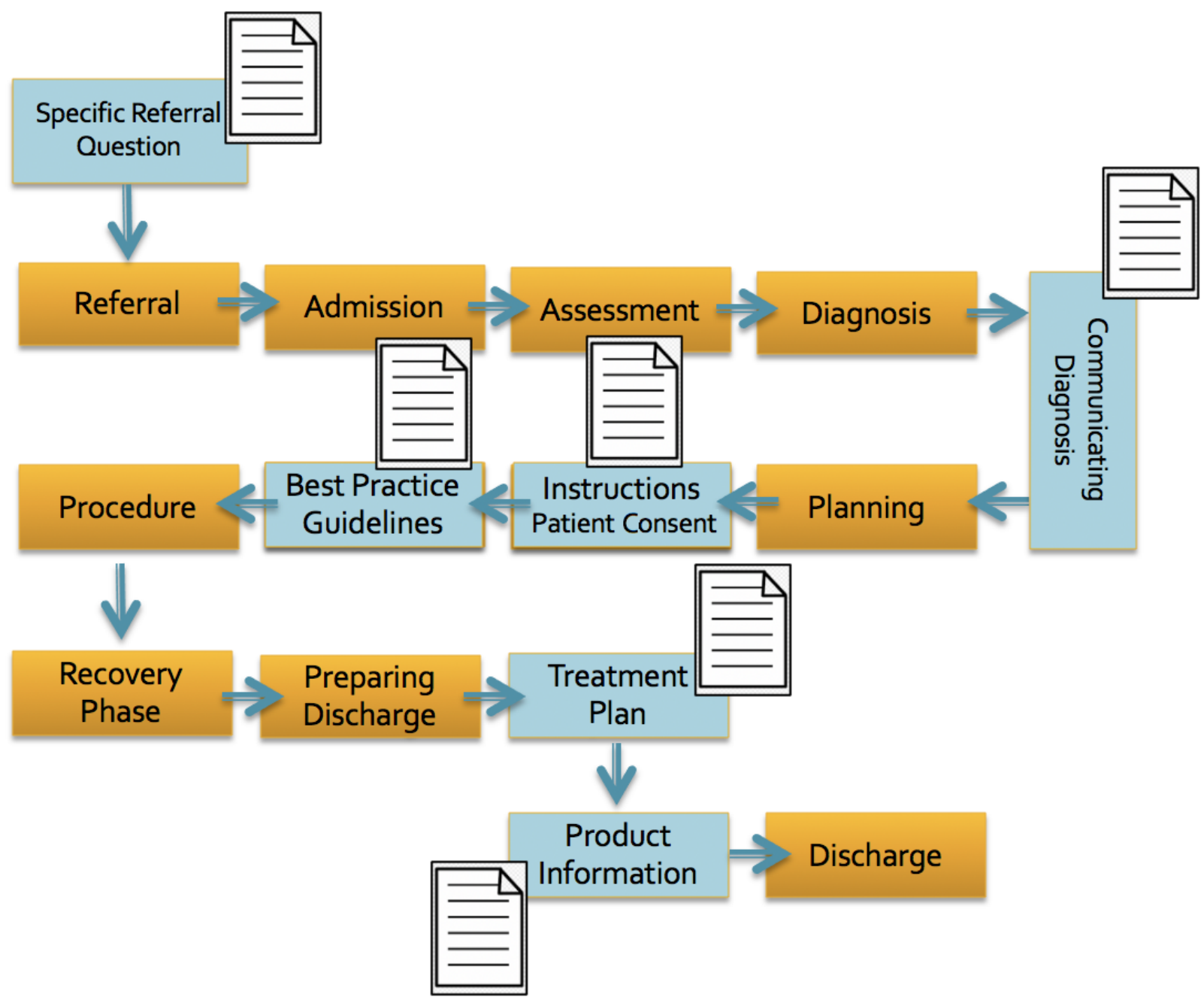


This is also in contrast to the fact that health literacy - the ability to read, write, and understand-has been recognized as an important milestone of the empowerment learning process for patients [14]. Health literacy allows the patients to perform knowledge-based literacy tasks in order to acquire, understand, and use health information for making their own health-related decisions. It has been postulated that these skills-applied in various environments, such as a home, community, or health clinic setting — will help the informed patient to prevent medical mistakes and increase their safety [15].

Lack of health literacy with subsequent misinterpretation of written material is still a current concern. In the European Health Literacy Survey, 1 in 2 (47\%) out of 8000 participants in eight different European countries had limited (ie, insufficient or problematic) health literacy [16]. Several studies confirmed that lack of health literacy has significant impact on safety, specifically on desired patient health outcomes. These include higher rates of medication errors as a result of misinterpretations of prescription drug label instructions [17], reduced patient recollection and understanding of informed consent [18], decreased cancer screening and immunization rates, and, finally, more emergency department use [19]. Furthermore, a very recent systematic review evaluated the readability of online health information in the United States and Canada: based on 3743 references, 157 cross-sectional studies, and 13 different scales, the mean readability grade level was by far too difficult to comprehend for the targeted audience. It ranged from grades 10 to 15 , while a grade 6 reading level for the general public is recommended [20].

In the following section of this paper, we will introduce document-engineering methodology (DEM) for designing medical information. The idea of DEM comes from industries such as aviation and oil, which proposed that DEM will help users to prevent errors, measurably reduce risk for injuries, and, overall, increase safety by designing an easy-to-read document [21]. In an innovative approach, we introduce DEM for the first time to the medical field.

\section{Document-Engineering Methodology: A Cognitive Science-Based Approach?}

It has been well known for more than 100 years that the brain is not perfect at all; it naturally produces errors while receiving, selecting, and processing information. We will provide two famous examples from cognitive neuropsychology and behavioral science.

In 1907, the Hungarian neurologist and psychiatrist Bálint wrote, "It is a well-known phenomenon that we do not notice anything happening in our surroundings while being absorbed in the inspection of something; focusing our attention on a certain object may happen to such an extent that we cannot perceive other objects placed in the peripheral parts of our visual field, although the light rays they emit arrive completely at the visual sphere of the cerebral cortex" [22].

The natural limitation of the brain to process and identify all visual information at the same time was further supported by the behavioral experiment of Simons and Chabris [23]. In their seminal paper, the authors describe an experiment in which a dancing gorilla was entirely missed on a video by observers when they were told to strictly focus on ball contacts of two teams of basketball players playing in front of the dancing gorilla. This phenomenon was subsequently called "inattentional blindness."

Document design as a new research field integrated these basic insights of the brain processing visual information and added several other components. Karen Schriver, an early scientist in technical writing, pioneered this approach. Her groundbreaking, extensive research is summarized in the comprehensive textbook Dynamics in Document Design: Creating Text for Readers [24]. Her insights about writing, reading, and visualizing documents defined the art of document design. The author emphasizes the importance of typography and space to improve readability and communication. Well-known principles of Gestalt psychology (ie, closure, symmetry, asymmetry, proximity, similarity, continuity, grouping, hierarchy, and balance) are implemented in the framework of document design [24].

Document design, with the main question on how we process and read written information, has been influenced by a multidisciplinary field of research. It spans over four decades and ranges from the classic psychological theory of reading by Just and Carpenter [25] to studying neuronal networks and circuits via advanced magnetic resonance imaging techniques while reading. The focus of this research was on visualization of subtle sequential processing steps within the brain while reading [26,27]. Other studies addressed the role of eye tracking for scanning and skimming written information, an issue that gets even more important in a fast-paced modern world using short messages for information dissemination on smartphones and other portable devices [28].

More recent research focuses on the user perspective in industry and how the user processes and reads procedural instructions [29]. The author suggests that the user consults a document in an interactive way rather than reading it in a linear manner [29]. Document design factors based on cognitive neuropsychology are introduced to allow reading with understanding, action planning, carrying out specific actions, and executive control activities [29]. These document design characteristics include a chronological or modular organization of the text, clear and precise headings, and using textual instructions where the word order strictly corresponds with the required action, question, or task to fulfil [29]. Design rules and design models based on cognitive and perceptual science have been proposed to further support engineering methods for interactive system design [30].

These approaches are in line with our recently proposed model [31] that readers (of books) and users (of written information) have different mindsets (see Figure 2 [31]). While the mindset of readers is driven by curiosity (ie, seeks reading for entertainment), users want to have immediate answers to their questions, often with a sense of urgency. Users need to be able to quickly navigate written information and need to be enabled to perform a specific action [31]. Recognizing the different mindsets between a reader and a user has enormous implications for designing a document. 
Figure 2. Two mindsets of processing and perceiving written information: readers reading versus users reading [31].

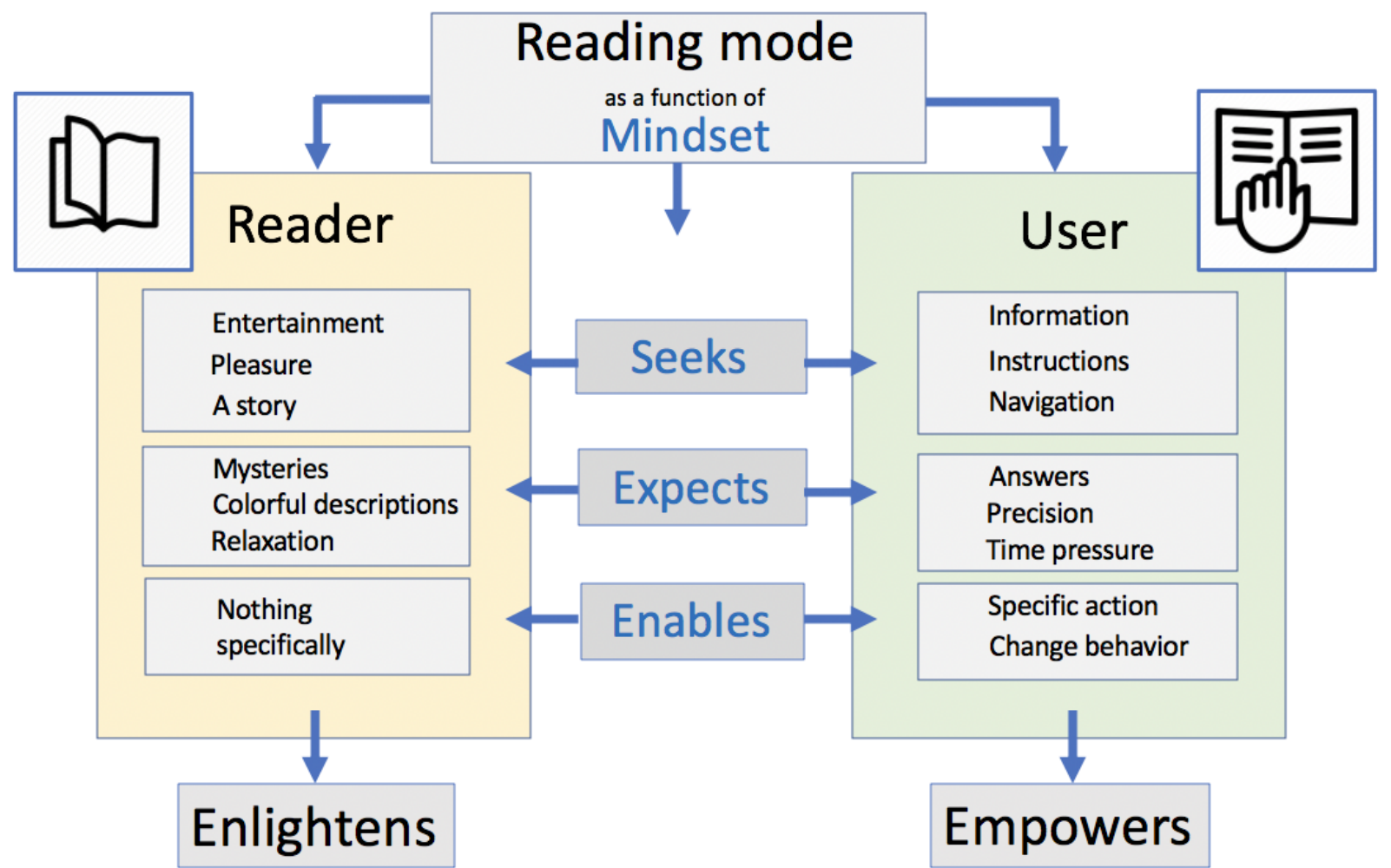

The original term document engineering comes from the software and hardware computer industry [32]. In its strictest sense, it is a document-centric synthesis of complementary ideas from information and systems analysis, electronic publishing, business process analysis, and business informatics. It attempts to unify these different analysis and modeling perspectives and helps to specify, design, and implement documents and the processes that create and consume them [32].

The way we will use the term document engineering is quite different from the original description. We define DEM as an innovative subspecialty methodology of document design-implementing principles of cognitive science and neuroscience. The engineering part in our approach to DEM refers to our process of putting parts together of the outlined frameworks required to process written information in the most effective way [24-29]. Applying this current scientific knowledge, we hypothesize that DEM will enable the user, in our case the patient, to easily read and understand written information and to perform actions and tasks quickly, safely, and efficiently.

Several industries outside of health care have used DEM in order to improve user performance, prevent harm, and increase safety. Proof-of-concept research studies are unfortunately missing. The biggest lessons learned come from the aviation industry, where safety is the number one priority and difficult-to-read, user-unfriendly information has repeatedly caused fatal and avoidable incidents [33].

Corporate psychology in the oil and gas industry has also applied this behavioral science-based methodology to help the brain navigate more easily through complex document-based information, such as procedural instructions. However, the statement "The user is enabled to take the right action fast and efficiently with measurably reduced risk of harm, hereby increasing safety" [21] still needs reconfirmation through practical research-based trials.

\section{DEM-1-Pager to Ease Communication in Health Care}

We suggest use of the DEM in health care. It is an opportunity to further establish the methodology and to test its added value in controlled trials. We provide three illustrative examples for potential use of a DEM-1-pager. In all three proposed examples, we produced an easy-to-read, single-page document, following DEM. The two authors of this paper pioneered and introduced the concept of DEM-1-pagers to health care only recently [31]. We use this as our first example in this manuscript.

As our target group, we chose people with a complex brain disease called psychogenic nonepileptic seizures (PNES). We sensed the suffering and the confusion of the people affected by PNES as we talked with them. They expressed, in particular, their frustration regarding insufficiently easy-to-understand learning material about their condition when communicating with their health care providers. People with PNES struggle with several challenges [34]. They face the overwhelming complexity of their disorder, they do not understand the underlying causes and prognosis, they recognize the lack of education around all stakeholders, they experience lots of obstacles and barriers in the health care system, and, most 
importantly, they are ill- informed right from start of their diagnosis of PNES [31,34].

Our way out of this dilemma was to produce a new communication tool in close collaboration with PNES patients: a DEM-1-pager. Our DEM-1-pager is content engineered for users-it is not written for readers.

We used a user-friendly, promise-question-answer (PQA) format as introduced in the oil and mining industry through corporate psychologists [21]; BP, one of the authors, is certified for this methodology. The PQA table is a basic framework with a heading and two columns; it consists of a promise presenting as the heading of the document (ie, the overriding topic the reader can expect). Organized on the left side of the document in a separate column are the most relevant questions. On the right side of the document are the answers strictly addressing the questions in simple terms.

We controlled for easy comprehension and readability by using a low Flesch-Kincaid reading level of seven [35]. The Flesch-Kincaid grade level is calculated by using a statistical program and the Flesch-Kincaid Grade Level Formula. The complex formula considers the number of words and syllables within a sentence. It measures the simplicity of writing and is widely used by teachers, librarians, educators, and others to assess the readability level of written text. We further embedded document design techniques from behavioral and Gestalt psychology $[24,30]$. The most important ones were limiting the questions to list to a maximum of seven items [36], implementing cognitive linking (ie, questions and answers containing similar wording) [29], and using behavioral enforcers
[29]. We are aware that the "magic number of seven" has initiated a controversial discussion among neuropsychologists; it is also an excellent illustration for a frequent dilemma in cognitive science-based experimental findings. A rather low amount of research has followed on the numerical limit of capacity in working memory [37,38].

The outlined design techniques will enable the patients to navigate fast and efficiently through this document and quickly find answers to their pressing questions. Our tool provides the patient with the most important, essential information about PNES, including the relevant obstacles from the health care system. Our DEM-1-pager is not meant to replace available comprehensive and often time-consuming information either published on paper or online [39]; rather, it is meant to be complementary to these valuable resources. Ideally, it can be used in the initial communication between PNES patients and health care professionals.

We engaged a group of PNES patients and cocreated with them the DEM-1-pager using a design-thinking process with many iterations [31]. We subsequently tested our DEM-1-pager in a small focus group of PNES patients; it was found to be beneficial in several domains. It also empowered patients to make their own decisions [31]. Figure 3 [31] shows the final version of a DEM-1-pager for PNES. The result is a poignant DEM-1-pager without overwhelming and confusing information.

Textbox 1 lists a range of other, randomly chosen, frequently occurring, complex medical conditions in which a DEM-1-pager can be helpful and contribute to early patient engagement. 
Figure 3. Document-engineering methodology (DEM)-1-pager for psychogenic nonepileptic seizures (PNES) (version 4); a tool for early communication of PNES created in a design-thinking process with patient engagement [31].

\section{Understanding PNES, A Patient Guide}

What does PNES stand for?

What causes PNES?

How is PNES

diagnosed?

How is PNES treated?

What is critical to assure a successful therapy?

What improves the prognosis?

What are the challenges?
PNES is a medical acronym which stands for Psychogenic Non-Epileptic Seizure

The causes of PNES are multifold including psychological, social and medical causes. The causes vary from person to person and can be difficult to be identified. The condition is real, and people with PNES are not faking.

PNES is usually diagnosed by neurologists with expertise in epilepsy. PNES is diagnosed by corroborating that the clinical symptoms during a seizure are not explained by electrophysiological abnormalities on Video-EEG. There are "positive clinical signs" which are highly characteristic for PNES.

\section{A PNES treatment approach consists of several steps which include:}

- Careful explanation of the diagnosis

- Exploration of medical \& psychosocial factors that are predisposing and precipitating

- Initiating evidence- and skills-based psychotherapy

- Regular follow-ups for outcome control

- PNES therapy typically involves a team of specialist clinicians who understand this disorder

Several key events are critical to a successful therapy. Amongst them are:

- Accept the diagnosis

- Access to a health care professional with expertise in PNES treatment

- Establish and maintain a trust relationship with your care team

- Educate yourself about PNES - become an expert.

The prognosis is much better when treatment starts early and worse if delayed. Unfortunately, data from large studies is lacking, and long-term prognosis is poorly understood at this time.

The challenges for people with PNES are:

- PNES occur in patients who also experience or have experienced epileptic seizures

- Health professionals are still learning about PNES

- Health care systems do not consistently offer the multidisciplinary \& integrated care needed in PNES

- The network of specialists needs to be developed

- There is insufficient public awareness.

Further reading http://www.nonepilepticseizures.com 
Textbox 1. Examples of complex diseases in which a document-engineering methodology (DEM)-1-pager of information could be useful.

- $\quad$ Psychogenic nonepileptic seizures

- $\quad$ Autism spectrum disorder

- Bipolar disorder

- $\quad$ Posttraumatic stress disorder

- Attention deficit hyperactivity disorder

- Diabetes mellitus

- Colon cancer

- Parkinson disease

- Fibromyalgia

- Chronic fatigue syndrome

- Alzheimer disease

- Many more diseases

As a second example, we chose patient information leaflets. Information leaflets are purposefully exhaustive and detailed in order to meet all medico-legal requirements. Patients often feel overwhelmed with the extent of written medical information, find it useless, and even tend to throw it away [40]. Patient information leaflets often are extremely wordy and not well designed and patients find it hard to navigate them. The leaflets almost never have a grade 6 readability level as a basic requirement. They often do not meet patients' needs and appear ineffective [41]. Patients cannot find the information they seek or may be confronted with nonessential material, affecting patients' perceptions of the leaflets and willingness to read them [42]. Applying DEM principles to information leaflets will hopefully reduce redundant words, improve format and design, and take health literacy (ie, grade 6 readability) into account.

As stated earlier, we do not suggest replacing patient information leaflets-we do see the necessity to present medico-legal information in the most complete and comprehensive way. However, we believe a complementary, easy-to-read DEM-1-pager will enhance the willingness of the patient to consider their suggested medication, for example.

We provide an illustration of this approach. The lead author of this paper (BP) is a seizure expert and subject matter expert. He applied DEM to a comprehensive, 18-page, official US Food and Drug Administration (FDA) patient information leaflet for brivaracetam, a newly licensed medication for seizure control [43]. The result is a DEM-1-pager (see Figure 4) that contains all essential information. The DEM-1-pager can help to start an initial communication about brivaracetam. Readability of a document encourages the patient to be compliant and become an informed partner. The 18-page FDA information leaflet is a critical complementary resource at any time. 
Figure 4. User-friendly, document-engineered methodology (DEM)-1-pager for the antiepileptic drug brivaracetam.

Brivlera (Brivaracetam) Product Information in a Nutshell

What is Brivlera?
How does Brivlera
work?
How is Brivlera
taken?
What is the
recommended
dosage of Brivlera?

What are typical side effects of Brivlera?

What are serious side effects of Brivlera?

When should I be cautious before using Brivlera?
Brivlera is a new medication, which effectively treats epileptic seizures. It is named after the molecule Brivaracetam. It is currently licensed in Canada to treat partial-onset seizures in the adults in combination with other antiseizure drugs. It is marketed by the pharmaceutical company UCB.

Brivlera works via a unique mechanism, which is not yet fully understood. It's mode of action is likely very different from most of other available antiseizure drugs. It suppresses seizures by stopping the seizure spread.

Brivlera can be taken as tablets of $10,25,50,75$, and $100 \mathrm{mg}$, as oral solution $(10 \mathrm{mg} / \mathrm{mL})$, and as injection $(10 \mathrm{mg} / \mathrm{mL})$

The recommended starting dosage is $50 \mathrm{mg}$ twice a day in adults. Some patients may need a slow increase and a starting dosage of 25 twice a day with an observation period of one week before further increase. The maximum daily dosage is twice a day $100 \mathrm{mg}$.

Typical side effects of Brivlera are:

- Dizziness, nausea \& vomiting, headache

- Feeling tired or fatigue, sleepiness \& drowsiness

- Poor coordination \& irritability

These side effects are often transient \& disappear within the first few weeks

Serious side effects of Brivlera are:

- Worsened emotional problems, thoughts of suicide or hurting yourself This side effect is uncommon - Needs immediate medical attention

- Allergic Reaction with swelling in the mouth, tongue, face and throat, itching, or rash, bronchospasm and angioedema, difficulty swallowing or breathing, wheezing, hives and generalized itching, fever, abdominal cramps, chest discomfort or tightness. This side effect is rare - Needs immediate medical attention

- Severe allergic skin reactions: all described above symptoms plus peeling of the skin, blisters, body aches, or swollen glands, fever, chills. This side effect is extremely rare - Needs immediate medical attention

I should be cautious before using Brivlera, when I had the following conditions:

- Rash or any other skin reaction with other medications in the past

- Allergic reaction to lactose (Brivlera tablets contain lactose)

- Depression, mood problems, suicidal thoughts, behavioral problems.

- Impaired liver or kidney function

I should be cautious when planning pregnancy as of lack of data with this drug
[44]. The use of CBM is still stigmatized, and health care providers are often reluctant to prescribe it. This is in contrast with the promising potential of CBM for multiple disorders and established clinical indications, such as epilepsy and pain [45].

The main author of this paper (BP) and other subject matter experts identified CBM as an ideal application for the use of a DEM-1-pager. Patients who seek treatment for chronic pain, one of the most accepted and evidence-based indications for CBM, want basic information about how CBM works. They 
are often desperate and seek knowledge through dialogue with their health care providers. These patients often encounter difficulties in finding answers to their most burning questions. They are confused and need navigation. Patients want to know how CBM might help them, information about side effects, how CBM can be consumed, how CBM is prescribed, which challenges they may face in the health care system, and so on.
Figure 5 shows a proposal of an easy-to-read DEM-1-pager addressing this patient problem. This document was created in a design-thinking process together with subject matter experts. It aims to help patients to easily find answers for their most relevant above-mentioned questions. This DEM-1-pager is a perfect start for a first dialogue between health care providers and patients on the topic of CBM. It is not meant to replace other valuable comprehensive resources.

Figure 5. Proposed document-engineering methodology (DEM)-1-pager for patients interested in medical cannabis.

\section{Medical Cannabis First Introduction for Patients}

Can cannabis ease my symptoms?

How does cannabis work?

Which common side effects can I expect?

How can I consume medical cannabis?

How is the dosage?

How do I get medical cannabis?

What are the challenges of treatment with medical cannabis?
Cannabis can ease your symptoms depending on a number of factors including your underlying medical condition. Cannabis has been used successfully in medicine since ancient times to treat a variety of symptoms. More recent studies have shown that cannabis can ease spasticity related to multiple sclerosis, chemotherapy-induced nausea and vomiting, chronic neuropathic pain and seizures in rare forms of childhood epilepsy.

Cannabis works through multiple pathways. It has more than $\mathbf{5 0 0}$ compounds. The best studied are the cannabinoids THC (tetrahydrocannabinol) \& CBD

(cannabidiol). A chemical process via heating (decarboxylation) is needed to unfold the therapeutic benefits. THC \& CBD modulate a complex system in the body called the "endocannabinoid system" (ECS). The ECS is found mainly in the brain and the immune system. THC \& CBD work through two main "receptors", CB1 and CB2, however impact many other functions and receptors.

You can expect the following common side effects: drowsiness, dizziness, anxiety, nausea, dry mouth, euphoria (THC only), and diarrhea if taking cannabis oil. Side effects tend to be mild and dose dependent. The more you take the more likely you are to experience a side effect. Side effects are usually reversible. This is not a full list of all possible side effects. Very rarely, THC can lead to psychosis in susceptible individuals.

You can consume medical cannabis in a variety of ways. Taking cannabis orally via an oil or a capsule has the highest dosing accuracy. You can choose between THCdominant and CBD-dominant, or balanced products with roughly equal amounts of THC and CBD. Other, safer ways to consume cannabis include skin cream or ointment and as a suppository.

The dosage is dependent on you individually as well as the prescribed compound:

- THC starting with $2.5 \mathrm{mg}$ on day 1 to a maximum of $20 \mathrm{mg} /$ day

- CBD starting with $3-5 \mathrm{mg}$ on day 1 to a maximum of $200 \mathrm{mg} /$ day

- The rule of thumb is to start with a low dose and slowly increase it over days and weeks to find your optimal dose.

You get medical cannabis in a relatively straight forward two-step process.

- You first need to get a Medical Document (like a prescription for cannabis) from a physician or nurse practitioner

- You then need to register for an account with a Licensed Producer to be enabled to order your medicine.

The challenges of treatment with medical cannabis are:

- Health care professionals are still learning about medical cannabis

- Medical cannabis is still stigmatized and prescribers are often reluctant

- Further clinical trials are needed to confirm the value of medical cannabis 
There are several limitations of the three provided examples of DEM-1-pagers. Only the first example, dealing with psychogenic nonepileptic patients [31], actively involved patients and health care professionals. This allowed a critical design-thinking process with reiterative feedback from users. The second and third examples lacked this process and still have to undergo testing in a focus group or in specific target groups. Some of the written content could certainly be replaced by colorful images to ease reading and understanding [29]. Active involvement of patients in designing these images is another intriguing opportunity for further templates.

We also see potential risks in using the presented DEM-1-pagers. They will always be simplifications of complex medical information. This goes along with the risk of likely not covering all individually highly relevant aspects. The patient may not seek out the more detailed complementary information, even when encouraged. This could harm the patient. It is, therefore, critical that the health care professional always explain the limitations of this tool to the patient.

\section{Conclusions}

Our paper encourages the consideration of DEM-1-pagers in several health care delivery environments where written medical information is relevant, complex, and widely used (see Figure 1), such as referral documents, consent forms, and instructions for treatment procedures, to name a few.

We anticipate that DEM-1-pagers will help health care professionals to initiate and strengthen the dialogue between the health care professional and the patient, helping to build trust. This can lead to empowerment on both ends. A DEM-1-pager is conceptualized to be a first step to explain essential information, followed by a more sophisticated and detailed discussion on the subject later on. We hypothesize that
DEM-1-pagers will help to improve patient guidance, empower the patient, and, ultimately, contribute to better outcomes.

We foresee a wide range of potential applications in the health care industry. We are fully aware of the limitations of our pilot data. Strong evidence is still lacking. Larger test studies will be needed to further validate DEM-1-pagers in various clinical scenarios. We, therefore, fully agree with a recent research paper mapping hypothesized impacts to suggested and assessed measures of patient, public, and stakeholder engagement. Their careful assessment confirmed lack of evidence underlying much of the impetus behind the practice of patient and stakeholder engagement in research, based on analyzing peer-reviewed literature using PubMed and PsycINFO databases from January 2005 to May 2013 [9].

We are also aware that we could not address all aspects of the impact of DEM in health care. It is, for example, beyond the scope of this paper to outline the health-economic and medico-legal aspects of patient and user empowerment by means of DEM-1-pager-designed documents. We also did not address the health-related preventive nature of well-written information; for example, poorly written child safety seat installation instructions have been found to be potentially harmful [46].

The main purpose of our paper is to encourage health care professionals to think in new ways about written medical documents for patients. The lessons from other industries about the usability of documents are intriguing. Cross-industry thinking carries a treasure of opportunities and will also facilitate breakthrough product innovation [47]. Safety is at stake if we do not open up to accept well-recognized and researched performance measures in these very industries. Health care is certainly still far behind in producing well-designed and user-friendly documents. DEM is a first step in this new uncharted territory.

\section{Conflicts of Interest}

None declared.

\section{References}

1. Gerteis M, Edgman-Levitan S, Daley J, Delbanco T, editors. Through the Patient's Eyes: Understanding and Promoting Patient-Centered Care. 6th edition. San Francisco, CA: Jossey-Bass; 2002.

2. Barry MJ, Edgman-Levitan S. Shared decision making: Pinnacle of patient-centered care. N Engl J Med 2012 Mar 01;366(9):780-781. [doi: 10.1056/NEJMp1109283] [Medline: 22375967]

3. Náfrádi L, Nakamoto K, Schulz PJ. Is patient empowerment the key to promote adherence? A systematic review of the relationship between self-efficacy, health locus of control and medication adherence. PLoS One 2017;12(10):e0186458 [FREE Full text] [doi: 10.1371/journal.pone.0186458] [Medline: 29040335]

4. Bravo P, Edwards A, Barr PJ, Scholl I, Elwyn G, McAllister M, Cochrane Healthcare Quality Research Group, Cardiff University. Conceptualising patient empowerment: A mixed methods study. BMC Health Serv Res 2015 Jul 01;15:252 [FREE Full text] [doi: 10.1186/s12913-015-0907-z] [Medline: 26126998]

5. Castro EM, Van Regenmortel T, Vanhaecht K, Sermeus W, Van Hecke A. Patient empowerment, patient participation and patient-centeredness in hospital care: A concept analysis based on a literature review. Patient Educ Couns 2016 Dec;99(12):1923-1939. [doi: 10.1016/j.pec.2016.07.026] [Medline: 27450481]

6. Hoffman A, Montgomery R, Aubry W, Tunis SR. How best to engage patients, doctors, and other stakeholders in designing comparative effectiveness studies. Health Aff (Millwood) 2010 Oct;29(10):1834-1841. [doi: 10.1377/hlthaff.2010.0675] [Medline: 20921483] 
7. Concannon TW, Meissner P, Grunbaum JA, McElwee N, Guise J, Santa J, et al. A new taxonomy for stakeholder engagement in patient-centered outcomes research. J Gen Intern Med 2012 Aug;27(8):985-991 [FREE Full text] [doi: 10.1007/s11606-012-2037-1] [Medline: 22528615]

8. Deverka PA, Lavallee DC, Desai PJ, Esmail LC, Ramsey SD, Veenstra DL, et al. Stakeholder participation in comparative effectiveness research: Defining a framework for effective engagement. J Comp Eff Res 2012 Mar;1(2):181-194 [FREE Full text] [doi: 10.2217/cer.12.7] [Medline: 22707880]

9. Esmail L, Moore E, Rein A. Evaluating patient and stakeholder engagement in research: Moving from theory to practice. J Comp Eff Res 2015 Mar;4(2):133-145. [doi: 10.2217/cer.14.79] [Medline: 25825842]

10. Lewis M. The Undoing Project: A Friendship That Changed Our Minds. New York, NY: WW Norton \& Company; 2016.

11. Coye MJ. No Toyotas in health care: Why medical care has not evolved to meet patients' needs. Health Aff (Millwood) 2001;20(6):44-56. [doi: 10.1377/hlthaff.20.6.44] [Medline: 11816688 ]

12. Poksinska B. The current state of Lean implementation in health care: Literature review. Qual Manag Health Care 2010;19(4):319-329. [doi: 10.1097/QMH.0b013e3181fa07bb] [Medline: 20924253]

13. Batalden PB, Davidoff F. What is "quality improvement" and how can it transform healthcare? Qual Saf Health Care 2007 Feb;16(1):2-3 [FREE Full text] [doi: 10.1136/qshc.2006.022046] [Medline: 17301192]

14. Pleasant A, Kuruvilla S. A tale of two health literacies: Public health and clinical approaches to health literacy. Health Promot Int 2008 Jun;23(2):152-159. [doi: 10.1093/heapro/dan001] [Medline: 18223203]

15. Nutbeam D, McGill B, Premkumar P. Improving health literacy in community populations: A review of progress. Health Promot Int 2018 Oct 01;33(5):901-911. [doi: 10.1093/heapro/dax015] [Medline: 28369557]

16. Sørensen K, Pelikan JM, Röthlin F, Ganahl K, Slonska Z, Doyle G, HLS-EU Consortium. Health literacy in Europe: Comparative results of the European Health Literacy Survey (HLS-EU). Eur J Public Health 2015 Dec;25(6):1053-1058 [FREE Full text] [doi: 10.1093/eurpub/ckv043] [Medline: 25843827]

17. Wolf MS, Davis TC, Shrank W, Rapp DN, Bass PF, Connor UM, et al. To err is human: Patient misinterpretations of prescription drug label instructions. Patient Educ Couns 2007 Aug;67(3):293-300. [doi: 10.1016/j.pec.2007.03.024] [Medline: 17587533]

18. Sherlock A, Brownie S. Patients' recollection and understanding of informed consent: A literature review. ANZ J Surg 2014 Apr;84(4):207-210. [doi: 10.1111/ans.12555] [Medline: 24812707]

19. Hersh L, Salzman B, Snyderman D. Health literacy in primary care practice. Am Fam Physician 2015 Jul 15;92(2):118-124 [FREE Full text] [Medline: 26176370]

20. Daraz L, Morrow AS, Ponce OJ, Farah W, Katabi A, Majzoub A, et al. Readability of online health information: A meta-narrative systematic review. Am J Med Qual 2018;33(5):487-492. [doi: 10.1177/1062860617751639] [Medline: 29345143]

21. How it works. Usability Mapping. URL: https://usabilitymapping.com/how-it-works [accessed 2020-04-30]

22. Bálint R. Psychic paralysis of gaze, optic ataxia, and disturbance of spatial attention. Orv Hetil 1907;1:209-236.

23. Simons DJ, Chabris CF. Gorillas in our midst: Sustained inattentional blindness for dynamic events. Perception 1999;28(9):1059-1074. [doi: 10.1068/p281059] [Medline: 10694957]

24. Schriver KA. Dynamics in Document Design: Creating Text for Readers. Hoboken, NJ: John Wiley \& Sons; 1997.

25. Just MA, Carpenter PA. A theory of reading: From eye fixations to comprehension. Psychol Rev 1980 Jul;87(4):329-354. [Medline: 7413885]

26. Carreiras M, Armstrong BC, Perea M, Frost R. The what, when, where, and how of visual word recognition. Trends Cogn Sci 2014 Feb;18(2):90-98. [doi: 10.1016/j.tics.2013.11.005] [Medline: 24373885]

27. Wandell BA, Le RK. Diagnosing the neural circuitry of reading. Neuron 2017 Oct 11;96(2):298-311 [FREE Full text] [doi: 10.1016/j.neuron.2017.08.007] [Medline: 29024656]

28. Duggan GB, Payne SJ. Text skimming: The process and effectiveness of foraging through text under time pressure. J Exp Psychol Appl 2009 Sep;15(3):228-242. [doi: 10.1037/a0016995] [Medline: 19751073]

29. Ganier F. Factors affecting the processing of procedural instructions: Implications for document design. IEEE Trans Prof Commun 2004 Mar;47(1):15-26. [doi: 10.1109/tpc.2004.824289]

30. Johnson J. Designing with the Mind in Mind: Simple Guide to Understanding User Interface Design Rules. Burlington, MA: Morgan Kaufman Publishers; 2010.

31. Pohlmann-Eden B, Eden SC, Smith R. Early communication is key: Designing a new communication tool to immediately empower people with psychogenic nonepileptic seizures. Epilepsy Behav 2019 Nov;100(Pt A):106518. [doi:

10.1016/j.yebeh.2019.106518] [Medline: 31665693]

32. Glushko RJ, McGrath T. Document Engineering: Analyzing and Designing Documents for Business Informatics and Web Services. Cambridge, MA: The MIT Press; 2005.

33. Strauch B. Investigating Human Error: Incidents, Accidents, and Complex Systems. 2nd edition. Boca Raton, FL: CRC Press; 2017.

34. Kanemoto K, LaFrance WC, Duncan R, Gigineishvili D, Park S, Tadokoro Y, et al. PNES around the world: Where we are now and how we can close the diagnosis and treatment gaps-An ILAE PNES Task Force report. Epilepsia Open 2017 Sep;2(3):307-316 [FREE Full text] [doi: 10.1002/epi4.12060] [Medline: 29588959] 
35. Williamson JML, Martin AG. Analysis of patient information leaflets provided by a district general hospital by the Flesch and Flesch-Kincaid method. Int J Clin Pract 2010 Dec;64(13):1824-1831. [doi: 10.1111/j.1742-1241.2010.02408.x] [Medline: 21070533]

36. Miller GA. The magical number seven plus or minus two: Some limits on our capacity for processing information. Psychol Rev 1956 Mar;63(2):81-97. [Medline: 13310704]

37. Doumont JL. Magical numbers: The seven-plus-or-minus-two myth. IEEE Trans Prof Commun 2002 Jun;45(2):123-127. [doi: 10.1109/TPC.2002.1003695]

38. Cowan N. George Miller's magical number of immediate memory in retrospect: Observations on the faltering progression of science. Psychol Rev 2015 Jul;122(3):536-541 [FREE Full text] [doi: 10.1037/a0039035] [Medline: 25751370]

39. Myers L, Jones J, Boesten N, Lancman M. Psychogenic non-epileptic seizures (PNES) on the internet: Online representation of the disorder and frequency of search terms. Seizure 2016 Aug;40:114-122 [FREE Full text] [doi:

10.1016/j.seizure.2016.06.018] [Medline: 27394057]

40. Koo MM, Krass I, Aslani P. Factors influencing consumer use of written drug information. Ann Pharmacother 2003 Feb;37(2):259-267. [doi: 10.1177/106002800303700218] [Medline: 12549958]

41. Raynor DK, Blenkinsopp A, Knapp P, Grime J, Nicolson DJ, Pollock K, et al. A systematic review of quantitative and qualitative research on the role and effectiveness of written information available to patients about individual medicines. Health Technol Assess 2007 Feb;11(5):iii-xi, 1-iii-xi160 [FREE Full text] [doi: 10.3310/hta11050] [Medline: 17280623]

42. Young A, Tordoff J, Smith A. 'What do patients want?' Tailoring medicines information to meet patients' needs. Res Social Adm Pharm 2017 Nov;13(6):1186-1190. [doi: 10.1016/j.sapharm.2016.10.006] [Medline: 27818214]

43. Prescribing information: Briviact. US Food and Drug Administration. 2017 Sep. URL: https://www.accessdata.fda.gov/ drugsatfda docs/label/2017/205836s003,205837s003,205838s002lbl.pdf [accessed 2017-09-30]

44. MacCallum CA, Russo EB. Practical considerations in medical cannabis administration and dosing. Eur J Intern Med 2018 Mar;49:12-19. [doi: 10.1016/j.ejim.2018.01.004] [Medline: 29307505]

45. Pertwee RG, editor. Handbook of Cannabis. 2nd edition. Oxford, UK: Oxford University Press; 2016.

46. Wegner MV, Girasek DC. How readable are child safety seat installation instructions? Pediatrics 2003 Mar;111(3):588-591. [doi: $10.1542 /$ peds.111.3.588] [Medline: 12612241$]$

47. Gassmann O, Zeschky M. Opening up the solution space: The role of analogical thinking for breakthrough product innovation. Creat Innov Manage 2008 Jun;17(2):97-106 [FREE Full text] [doi: 10.1111/j.1467-8691.2008.00475.x]
Abbreviations
CBM: cannabis-based medicine
DEM: document-engineering methodology
FDA: Food and Drug Administration
PNES: psychogenic nonepileptic seizures
PQA: promise-question-answer

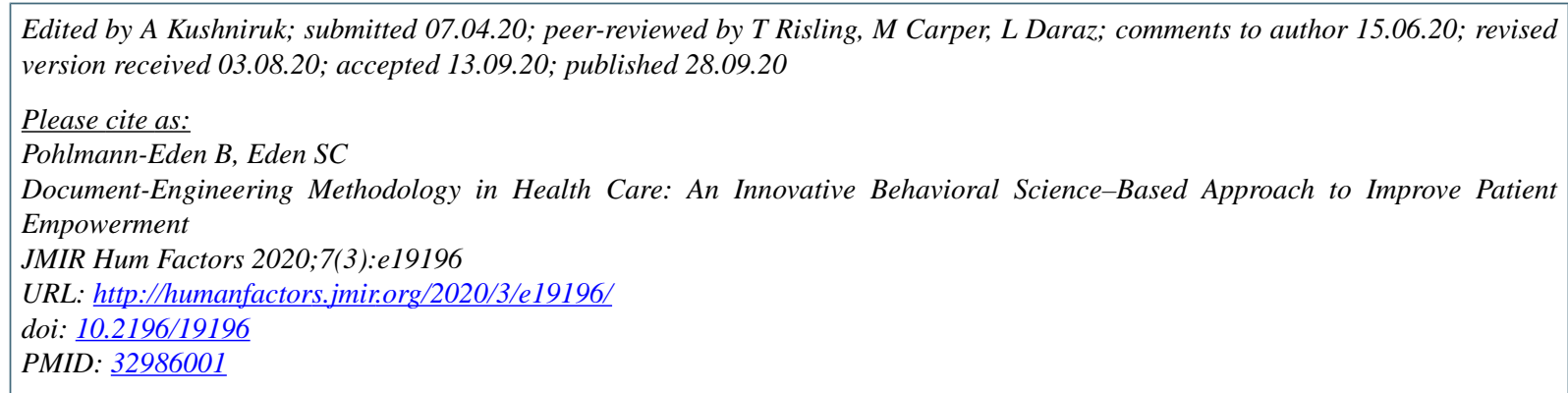

CBernd Pohlmann-Eden, Silke C Eden. Originally published in JMIR Human Factors (http://humanfactors.jmir.org), 28.09.2020. This is an open-access article distributed under the terms of the Creative Commons Attribution License (https://creativecommons.org/licenses/by/4.0/), which permits unrestricted use, distribution, and reproduction in any medium, provided the original work, first published in JMIR Human Factors, is properly cited. The complete bibliographic information, a link to the original publication on http://humanfactors.jmir.org, as well as this copyright and license information must be included. 